Discussion Paper No. 951

\title{
MONEY IN THE EQUILIBRIUM OF BANKING
}

\author{
Jin Cao \\ Gerhard Illing
}

December 2015

The Institute of Social and Economic Research

Osaka University

6-1 Mihogaoka, Ibaraki, Osaka 567-0047, Japan 


\title{
Money in the Equilibrium of Banking ${ }^{1}$
}

\author{
Jin Cao \\ Research Department, Norges Bank, Bankplassen 2, P. O. Box 1179 Sentrum, N-0107 Oslo, Norway \\ and CESifo, Germany \\ jin.cao@norges-bank.no \\ Gerhard Illing \\ Seminar für Makroökonomie, Ludwig-Maximilians-Universität München, Ludwigstrasse 28/012 \\ (Rgb.), D-80539 Munich, Germany and CESifo, Germany \\ illing@lmu.de
}

\begin{abstract}
In most banking models, money is merely modeled as medium for transaction, but in reality, money is also the most liquid asset for banks. Central banks do not only passively supply money to meet demand for transaction, as often assumed in these models, instead they also actively inject liquidity into market, taking banks' illiquid assets as collateral. We examine both roles of money in an integrated framework, in which banks are subject to aggregate illiquidity risk. With fixed nominal deposit contracts, the monetary economy with active central bank can replicate constrained efficient allocation. This allocation, however, cannot be implemented in market equilibrium without additional regulation: Due to moral hazard problems, banks invest excessively in illiquid assets, forcing the central bank to provide liquidity at low interest rates. We show that interest rate policy to reduce systemic liquidity risk on its own is dynamically inconsistent. Instead, the constrained efficient solution can be achieved by imposing ex ante liquidity coverage requirement.
\end{abstract}

Keywords: Central banking; liquidity facility; systemic liquidity risk

JEL classification: G21; G28

\section{Introduction}

After the financial crisis in 2008, concerns about financial stability and the disruption of financial intermediation have become a key focus for central banks. Unconventional monetary policy measures such as credit easing try to prevent systemic banking crises. At the same time, there are increasing concerns that accommodative monetary policy with ample liquidity provision may encourage excessive risk taking, resulting in a rapid increase in leverage of financial intermediation and so endangering financial stability in the future. Our paper tries to analyze the feedback mechanism between central bank actions and bank's incentives to cope with liquidity risk in a fiat money economy.

Traditional banking models are real models without fiat money. Even though they provide useful insights on the sources of financial instability, they are silent on the question what impact liquidity provision via fiat money has on financial stability in reality. Recently, several studies, such as Allen et al. (2014) and Skeie (2008), try to fill in this gap. In these models, money is mostly used only as the

\footnotetext{
${ }^{1}$ The views expressed in this paper are those of the authors and do not necessarily reflect those of Norges Bank.
} 
medium for transactions. The central bank is merely issuing bank notes passively to meet the money demand in transactions (in Allen et al., 2014 even the banks are passive: they pass deposits to firms which make decisions on investment portfolios). As a result, the (constrained) efficient equilibrium can always be achieved as long as depositors' nominal claims are met.

However, in reality fiat money is not only the medium for transaction, but also the most liquid asset in banking sector. Central banks take a much more active role by providing liquidity to the economy. Traditionally, the quantity theory of money focuses on the role of money as medium for transaction, with the price level being determined by the aggregate supply of money. The new Keynesian ("Woodfordian") monetary theory focuses on interest rate adjustments as mechanism for stabilizing the price level. However, in both perspectives banks are essentially doing nothing more than passively transmitting money into the real economy. The contribution of this paper is to capture both perspectives in one framework, analyzing the impact of banks' strategies on money demand, inflation, and financial stability in a purely monetary economy.

Apart from monetizing transactions, central banks also conduct active monetary policy, using shortterm interest rate to affect banks' refinancing cost in the market for liquidity. Here, banks use their illiquid assets - which provide return in the future - as collateral to raise money as liquid asset in order to meet depositors' demand for liquidity today. Money as liquidity and central bank's monetary policy practice have profound implications for financial stability: banks react actively to the path of central bank's policy rate, exploiting central bank's liquidity facilities to reshuffle resources across periods, whenever possible, by increasing the share of high-yield illiquid assets in their investment portfolios. Such strategic feedback between central bank's monetary policy and banks' investment decisions, as this paper shows, may become a source of systemic risk such that the economy gets stuck in an inferior equilibrium.

\subsection{Related literature}

Freixas, Martin and Skeie (2011) analyze the efficiency of the interbank lending market in allocating funds and the optimal policy of a central bank in response to liquidity shocks. They show that, during an aggregate liquidity crisis, central banks need to manage both interest rates and liquidity injection (the aggregate volume of liquidity). In their model, failure to cut interest rates during a crisis erodes financial stability by increasing the probability of bank runs. They do not, however, address the feedback mechanism between central bank's policy and the incentives of the banking system to invest in private provision of liquid assets.

Allen, Carletti and Gale (2014) introduce nominal contracts in a banking model with idiosyncratic and aggregate liquidity risk. They show that the first-best efficient allocation can be achieved in a decentralized banking system when the central bank accommodates the demands of the private sector for fiat money. In their model, variations in the price level allow full sharing of aggregate risks. Their paper, however, does not analyze how financial intermediaries react ex ante to anticipated liquidity injections by the central bank. The probability of an aggregate liquidity shock is not affected by the amount of private investment in liquid assets. In contrast, our paper focuses explicitly on the endogenous response of private banks to liquidity injections. We show that they engage in activities creating systemic risk by investing in less liquid assets.

Our paper extends Cao and Illing (2011). That paper characterizes incentives for private liquidity provision in a static framewok when the central bank mitigates fragility of the financial system arising from banks liquidity transformation via nominal deposit contracts. Here, we analyze a repeated setting of Cao and Illing (2011), focusing on the case that systemic shocks are extremely rare events. In case 
of a systemic shock, the central bank, trying to prevent costly bank runs, provides additional paper money to the banks. Lender of last resort policy prevents interest rates from shooting up in case of systemic risk, ensuring that banks are always able to pay out their nominal commitments. We show that the central bank may be forced to keep interest rates low for an extended period, crowding out private liquidity provision.

\subsection{Structure of the paper}

Section 2 presents the structure of the model in a real economy in the absence of central bank activity and fiat money. It characterizes the constrained efficient solution for the pure market case. Banks engaged in maturity transformation have an incentive to hold liquid assets to meet depositors' demand for idiosyncratic risks But negative aggregate liquidity shocks trigger system-wide bank runs, generating huge social costs. Section 3 shows that in a decentralized monetary economy with the central bank providing money both as medium of transaction as well as bank liquidity, banks can get access to liquidity through central bank's interday loans, using their long maturity assets as collateral. Costly bank runs can be eliminated and the constrained efficient allocation can be replicated. However, section 4 shows that this allocation cannot be implemented as dynamic consistent equilibrium due to the moral hazard arising from the central bank's commitment to provide standing liquidity facilities, so the monetary economy ends up in an inferior equilibrium. Section 5 further shows that the same result holds in the long-run equilibrium. In the absence of aggregate liquidity risk, banks can perfectly hedge against idiosyncratic risks in the real economy by holding liquidity buffer, however, section 6.1 shows that the incentive for private liquidity provision will be crowded out in the monetary economy. To achieve constrained efficiency, section 6.2 suggests that due to the time-inconsistency problem central bank's liquidity facility should not condition on the banks' liquidity; instead, liquidity support should be made contingent on the banks' fulfilling liquidity constraints as entry requirement. Section 7 concludes.

\section{The real economy}

In this section we consider the real economy. Following Cao \& Illing (2011), we describe the source of liquidity risk and, as the baseline result for the rest of the paper, characterize the constrained efficient allocation.

\subsection{The model setup}

Consider the following economy with three types of risk neutral agents: depositors, banks (run by bank managers), and entrepreneurs. The economy extends over three periods, $t=0,1,2$, and the details of timing will be explained later. We assume that:

(i) There is a continuum of depositors, each being endowed with one unit of resources at $t=0$. They will be willing to deposit in banks as long as the real return is (weakly) larger than 1 . Depositors are impatient: they want to withdraw and consume at $t=1$; in contrast, banks and entrepreneurs are indifferent between consuming at $t=1$ and $t=2$;

(ii) There is a finite number $N$ of active banks participating Bertrand competition, competing for depositors' deposits at $t=0$. Using these deposits, banks as financial intermediaries can fund projects of entrepreneurs; 
(iii) There is a continuum of entrepreneurs, and there are sufficiently many entrepreneurs competing for funds so that bank deposits are scarce. Each of the entrepreneurs runs one of two types of the projects:

- Safe projects, which are realized early at $t=1$ with a safe return $R_{1}>1$.

- Risky projects, which give a higher return $R_{2}>R_{1}>1$. With probability $p$, these projects will be realized at $t=1$, but the return may be delayed (with probability $1-p$ ) until $t=2$. Therefore, in the aggregate, the share $p$ of type 2 projects will be realized early. The value of $p$, however, is not known at $t=0$. It will only be revealed between period 0 and 1 at some intermediate period, $t=\frac{1}{2}$. In the following, we are interested in the case of aggregate shocks to all risky projects (but we will discuss idiosyncratic shocks later): The value of $p$ can be either $p_{H}$ or $p_{L}$ with $p_{H}>p_{L}$. The "good" state with $p=p_{H}$ will be realized with probability $\pi$. Since the "bad" state, or the "crisis" state, is rare, we assume that $\pi$ is almost $1^{2}$. In the following, we further assume that $1<p_{s} R_{2}<R_{1}(s \in\{H, L\})$ to focus on the relevant case. ${ }^{3}$

At $t=0$ banks compete for depositors by offering them fixed deposit contracts that promise a return $d_{0}$ at $t=1$. At the same time, banks decide the proportion $\alpha$ of deposits to be invested in the safe assets. Depositors have rational expectations: they deposit in banks that offer them the highest expected return.

At $t=\frac{1}{2}$ the value of $p$ is revealed, and this is public information. Given the value of $p$, if one bank will not be able to meet its depositors' claims at $t=1$, the depositors will run on the bank at $t=\frac{1}{2}$ because of first-come-first-served rule. If a bank experiences a run at this date, it has to liquidate all unmatured assets, i.e., both safe and risky projects. Each unit of liquidated asset yields a poor return $c<1$.

If there is no bank run, banks collect a proportion $\gamma$ from the return of early projects (safe projects plus those risk projects that return early) and early entrepreneurs retain the rest (the implication of $\gamma$ will be explained later). To maximize depositors' return, banks can raise more funds from early entrepreneurs in liquidity market: banks borrow from early entrepreneurs, promising a borrowing rate $r$ and using their late projects as collateral. Since entrepreneurs are indifferent between consuming at $t=1$ and $t=2$, they will be willing to lend to banks as long as $r \geq 1$. Banks make payout to depositors using the return collected from early projects and the liquidity borrowed from liquidity market.

At $t=2$ banks collect return from late projects and pay back early entrepreneurs.

If there were no financial friction, depositors would contract directly with entrepreneurs, investing entirely in the safe projects, and receive all the return at $t=1$. However, due to hold up problems as modeled in Hart \& Moore (1994), entrepreneurs can only commit to pay a fraction $\gamma$ of their return (assume that $\gamma R_{i}>1$ ). Banks as financial intermediaries are assumed to have better collection skills (higher $\gamma$ ) than depositors, so that depositors become better off by depositing their endowments in

\footnotetext{
${ }^{2}$ As long as $\pi \in\left(\frac{\gamma E\left[R_{L}\right]-c}{\gamma E\left[R_{H}\right]-c}, 1\right)$ with $E\left[R_{S}\right]=\alpha_{S} R_{1}+\left(1-\alpha_{S}\right) R_{2}(s \in\{L, H\})$ and $\alpha_{S}=\frac{\gamma-p_{S}}{\gamma-p_{S}+(1-\gamma) \frac{R_{1}}{R_{2}}}$. This allows us to focus on the case that the cost of bank failure is small enough that banks can take more liquidity risk instead of investing higher share on liquid assets to avoid bank runs completely.

${ }^{3}$ In that case, depositors care about the share invested in liquid projects. On the other hand, due to financial frictions captured by the hold-up problem as characterized at the end of this section, depositors gain from banks also investing some share in illiquid projects.
} 
banks. However, as is shown in Diamond \& Rajan (2001), banks then have the incentive to abuse their collection skills and force depositors to renegotiate at $t=1$, making deposit contracts break down. To avoid this, banks need to offer fixed deposit contracts, as is assumed in this paper, and depositors are privileged to run once they perceive that banks cannot meet the contracts, leaving all banks' assets destroyed. The threat of bank run is thus a device to discipline banks to respect deposit contracts.

\subsection{The constrained efficient allocation}

The baseline of the model is the constrained efficient allocation, achieved from the solution of the social planer's problem. This will be the reference point for the market equilibrium characterized in the next section, when banks serve as financial intermediaries. Assume that the social planner has the same collection skill (the same $\gamma$ ) as banks, and she maximizes the depositors' real return by choosing a portfolio of safe and risky assets. The result is characterized in the following proposition:

Proposition 1 The constrained efficient allocation is featured by

(1) At $t=0$ the planner invests a share $\alpha_{H}=\frac{\gamma-p_{H}}{\gamma-p_{H}+(1-\gamma) \frac{R_{1}}{R_{2}}}$ on the safe assets, and the depositors' expected return at $t=1$ is $E\left[R\left(\alpha_{H}\right)\right]=\pi \gamma E\left[R_{H}\right]+(1-\pi) \gamma E\left[R_{L}\right]$;

(2) When $p_{L}$ is realized at $t=\frac{1}{2}$, depositors' return at $t=1$ is $\alpha_{H} R_{1}+\left(1-\alpha_{H}\right) p_{L} R_{2}<$ $\gamma\left[\alpha_{H} R_{1}+\left(1-\alpha_{H}\right) R_{2}\right]$.

Proof See Appendix.

Since the social planner cannot reshuffle resources between periods and depositors only value consumption at $t=1$, a share of the funds should be invested in safe projects. However, depositors will also benefit from social planner's holding of risky assets, since social planner can raise additional liquidity from early entrepreneurs and maximize depositors' return, using the delayed risky projects as collateral. Given that the likelihood of a bad state is low, the social planner should choose the investment portfolio such that it maximizes depositors' return in the good state; while in the bad state, the abundant delayed projects allow social planner to use all the funds held by the early entrepreneurs at $t=1$ and return to depositors, even though depositors' return is lower than that in the good state.

\subsection{Market equilibrium}

In this section we consider a decentralized economy and characterize market equilibrium with banks. The equilibrium consists of banks' strategic profiles $\left(\alpha_{i}^{*}, d_{0 i}^{*}\right), \forall i \in\{1, \ldots, N\}$, that satisfy the following conditions:

Profit maximization of banks At $t=0$ every bank chooses its optimal proportion of investment in liquid assets $\alpha_{i}^{*}$ and deposit contract $d_{0 i}^{*}$ to maximize its expected return. That is, the bank makes lower profit if it chooses any different strategic profile

$$
\Pi_{i}\left(\alpha_{i}, d_{0 i}\right)<\Pi_{i}\left(\alpha_{i}^{*}, d_{0 i}^{*}\right), \forall\left(\alpha_{i}, d_{0 i}\right) \neq\left(\alpha_{i}^{*}, d_{0 i}^{*}\right) ;
$$

Zero profit No bank makes positive profit, as a result of Bertrand competition;

Return maximization of depositors At $t=0$ depositors deposit their endowments at those banks offering the highest expected return; 
Market clearing At $t=1$, if there is no bank run, the liquidity market is cleared by the interest rate $r$ which is offered to the early entrepreneurs by banks.

Since the bad state is a low probability event, banks can take more liquidity risk to maximize their return in the good state, ignoring the liquidation cost in the bad state. Banks' return is maximized when they can obtain the most liquidity at the lowest interest rate. By market clearing condition, the equilibrium interest rate is determined by the value of banks' late projects and the volume of liquidity (the rent retained by early entrepreneurs) - both are functions of $\alpha$. In the end, banks' decision problem boils down to choosing the optimal $\alpha$ so that banks can borrow in liquidity market at the lowest cost. The equilibrium can be characterized by the following proposition:

Proposition 2 Market equilibrium in the decentralized real economy is featured by

(1) At $t=0$ all banks set $\alpha^{*}=\alpha_{H}$ and offer $d_{0}^{*}=\gamma E\left[R_{H}\right]$;

(2) When $p_{H}$ is revealed, banks raise liquidity from liquidity market at $t=1$ at interest rate $r=1$ and repay depositors; when $p_{L}$ is revealed, banks experience runs and have to liquidate both safe and risky projects at $t=\frac{1}{2}$;

(3) Depositors' expected return is $\pi \gamma E\left[R_{H}\right]+(1-\pi) c$, which is inferior to that in the constrained efficient allocation.

Proof See Appendix.

Comparing with the constrained efficient solution as characterized in the last section, it is evident that in the decentralized economy banks do have the incentive to hold the same share of liquid assets in their investment portfolio, which maximizes depositors' return in the good state. However, when the bad state is revealed at $t=\frac{1}{2}$ and there is an aggregate liquidity shortage in the economy, banks cannot raise sufficient funding in the liquidity market. Although banks hold enough delayed projects which may serve as good collateral, depositors will run the bank, resulting in socially costly liquidation of all assets. In the next section, we show that costly bank run can be eliminated in a monetary economy, where there is a central bank providing money both as medium of transaction and bank liquidity, so the constrained efficient solution can be replicated.

\section{Constrained efficiency in a decentralized monetary economy}

In this section, we show that the constrained efficient allocation can be replicated in a decentralized monetary economy, improving efficiency comparing with that under market equilibrium.

From now on, following the model outlined in the last section, assume there is a central bank acting as monetary authority, with all deposit contracts being written in nominal terms. We distinguish two roles of money:

(1) Money as medium of transaction. In our monetary economy, all the transactions are committed via exchanges of cash versus goods. Fiat money is issued by the central bank to facilitate the transactions ("monetizing the economy"), and the quantity of money in circulation is equal to transaction demand for money. For simplicity, we assume that the quantity of money issued in each period is equal to the quantity of real goods in transaction, thus normalizing the price level in the absence of additional liquidity provision to 1 . 
(2) Money as liquidity. Banks can borrow additional fiat money from the central bank to meet their demand for liquidity subject to the central bank’s policy rate, using their illiquid assets as collateral.

Motivated by these two roles of money, monetary policy of the central bank is conducted through the following two kinds of operations:

(1) Money as medium of transaction is issued through intraday loans to banks during the period. Its quantity is equal to the quantity of real goods in transaction, and banks have to pay back the loans in the end of the period. This is the working mechanism of Allen, Carletti and Gale (2014);

(2) On the other hand, central bank is also a crucial liquidity provider to the banking sector: Money as liquidity is injected into the economy through interday loans to banks subject to the policy rate, using banks' long assets as collateral. The loans are paid back one period later, after the return of long assets materializes.

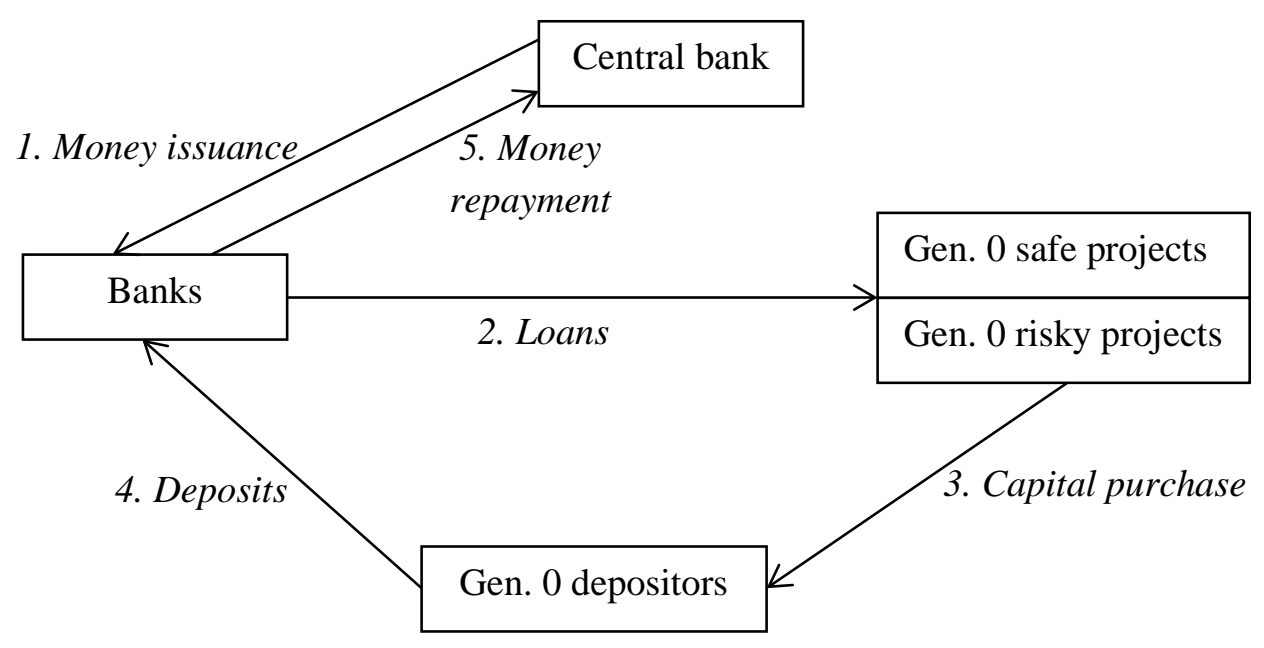

Figure 1 Monetizing the economy at $t=0$. The arrows show the direction of money flows, and the numbers indicate the sequence of money flows.

With a central bank providing both medium of transaction and liquidity, money is introduced to the economy in the following way:

At $t=0$

Figure 1 shows the flows of money and goods throughout the sequence:

1. Banks get 1 unit of intraday money loans from the central bank, which is equal to the entrepreneurs' demand for buying the endowments of the depositors;

2. Banks issue loans to the entrepreneurs, a share of $\alpha$ for the entrepreneurs running safe projects (short term loans), $1-\alpha$ for those running risky projects (long term loans);

3. Entrepreneurs use the loans to purchase the depositors' endowments, as capital input to their projects;

4. Depositors deposit the money in banks. Banks offer depositors the nominal demand deposit contracts that promise $d_{0}$ nominal return at $t=1$ for each unit of deposit; 
5. At the end of the period, banks pay back the loans to the central bank.

\section{At $t=1($ good state)}

Suppose at $t=\frac{1}{2}$ it is revealed that the economy will in the good state, Figure 2 shows the flows of money throughout the period $t=1$ :

1. Banks get $d_{0}$ unit of intraday money loans from the central bank, which is equal to the depositors' demand for buying the consumption goods from the entrepreneurs whose projects return early;

2. Banks repay $d_{0}$ to the depositors;

3. The depositors purchase $d_{0}=\alpha_{H} R_{1}+\left(1-\alpha_{H}\right) p_{H} R_{2}$ consumption goods from the early entrepreneurs;

4. Early entrepreneurs repay their loans, $\gamma\left[\alpha_{H} R_{1}+\left(1-\alpha_{H}\right) p_{H} R_{2}\right]$, to banks, and

5. Deposit $(1-\gamma)\left[\alpha_{H} R_{1}+\left(1-\alpha_{H}\right) p_{H} R_{2}\right]$ in banks;

6. At the end of the period, banks pay back the loans to the central bank.

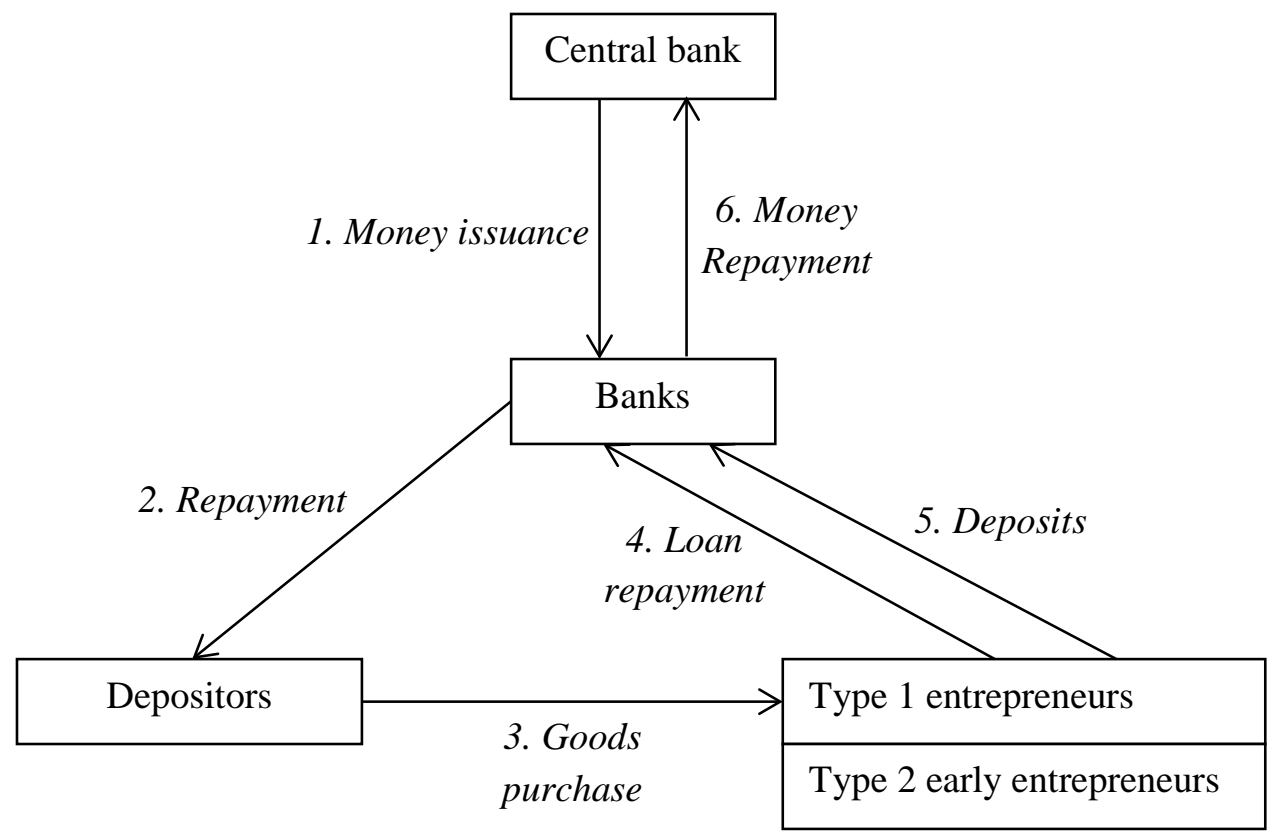

Figure 2 Money flows at $t=1$. 




Figure 3 Sequence of money flows at $t=2$ following the good state.

\section{At $t=2$ (after the good state)}

After the good state in period $t=1$, Figure 3 shows the flows of money throughout the subsequent period $t=2$ :

1. Banks get $(1-\gamma)\left[\alpha_{H} R_{1}+\left(1-\alpha_{H}\right) p_{H} R_{2}\right]$ unit of intraday money loans from the central bank, which is equal to early entrepreneurs' demand for buying the consumption goods from late entrepreneurs;

2. Banks repay $(1-\gamma)\left[\alpha_{H} R_{1}+\left(1-\alpha_{H}\right) p_{H} R_{2}\right]$ to early entrepreneurs;

3. Early entrepreneurs purchase $(1-\gamma)\left[\alpha_{H} R_{1}+\left(1-\alpha_{H}\right) p_{H} R_{2}\right]=\gamma\left(1-\alpha_{H}\right)\left(1-p_{H}\right) R_{2}$ consumption goods from the late entrepreneurs;

4. Late entrepreneurs repay their loans, $\gamma\left(1-\alpha_{H}\right)\left(1-p_{H}\right) R_{2}$, to banks;

5. At the end of the period, banks pay back all the loans to the central bank.

\section{At $t=1$ (bad state)}

In good times, the market equilibrium is constrained efficient and there is no need for the central bank in liquidity provision. However, if it is revealed at $t=\frac{1}{2}$ that the economy will in the bad state, the liquidity stress of banks can be alleviated by the central bank's interday facilities. The mechanism is shown as Figure 4:

1. When it comes to the repayment to the depositors, banks can only get a total of $\alpha_{H} R_{1}+$ $\left(1-\alpha_{H}\right) p_{L} R_{2}<d_{0}$ intraday loans from the central bank. Therefore

1.5 Banks get $\gamma\left(1-\alpha_{H}\right)\left(p_{H}-p_{L}\right) R_{2}$ liquidity through interday loans from the central bank using $\gamma\left(1-\alpha_{H}\right)\left(p_{H}-p_{L}\right) R_{2}$ illiquid assets as collateral, given the policy rate $r^{M}=1$;

2. Banks repay $d_{0}$ to the depositors;

3. The depositors purchase $\alpha_{H} R_{1}+\left(1-\alpha_{H}\right) p_{L} R_{2}$ consumption goods from the early entrepreneurs at a price $\frac{d_{0}}{\alpha_{H} R_{1}+\left(1-\alpha_{H}\right) p_{L} R_{2}}>1$;

4. Early entrepreneurs repay their loans, $\gamma\left[\alpha_{H} R_{1}+\left(1-\alpha_{H}\right) p_{L} R_{2}\right]$, to banks, and 
5. Deposit $\gamma\left(1-\alpha_{H}\right)\left(1-p_{L}\right) R_{2}$ in banks with gross interest rate 1 ;

The final step 6 is similar to Figure 2, except that banks only repay $\alpha_{H} R_{1}+\left(1-\alpha_{H}\right) p_{L} R_{2}$ intraday loans to the central bank, retaining $\gamma\left(1-\alpha_{H}\right)\left(p_{H}-p_{L}\right) R_{2}$ as liabilities to the central bank backed by the collateral.

At $t=2$ (after the bad state)

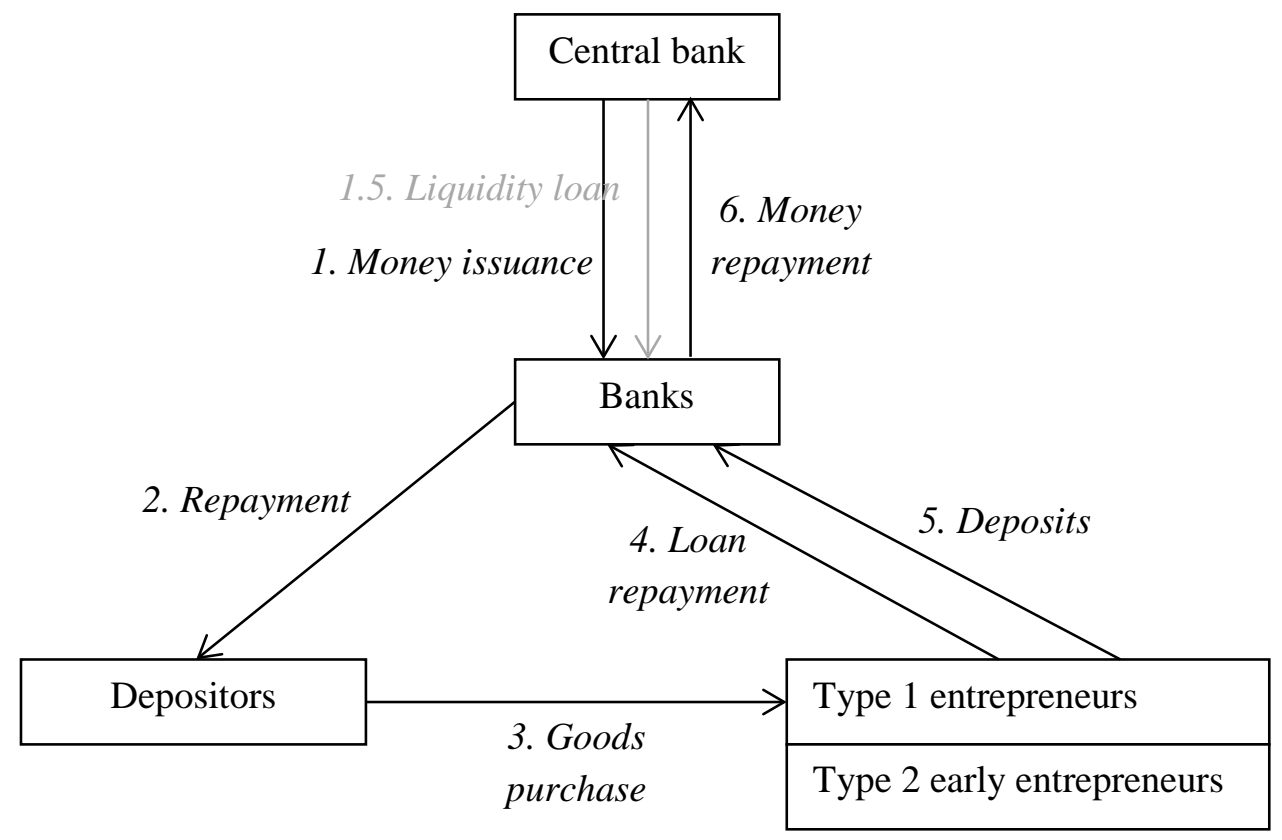

Figure 4 Sequence of money flows at $t=1$ in the bad state.

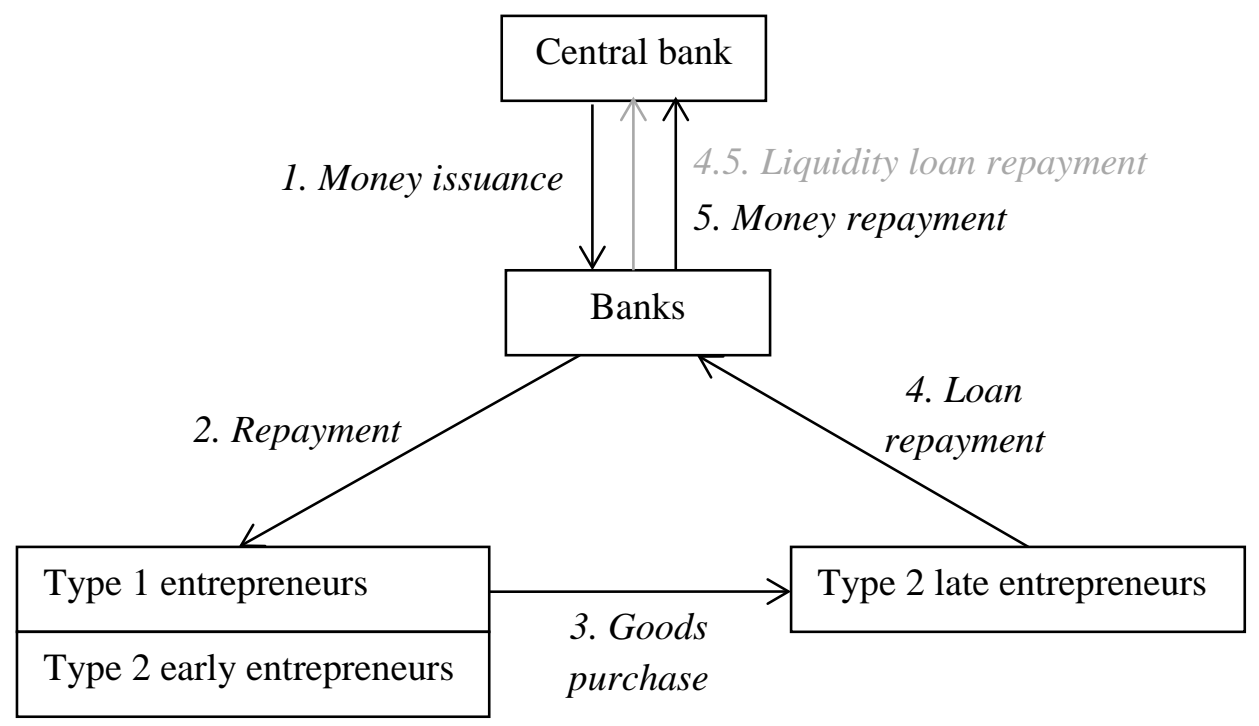


Figure 5 Sequence of money flows at $t=2$ following the bad state.

In the subsequent period $t=2$, banks need to repay the interday loans when the return of illiquid collateral is realized. As Figure 5 shows,

1. Banks get $\gamma\left(1-\alpha_{H}\right)\left(1-p_{L}\right) R_{2}-\gamma\left(1-\alpha_{H}\right)\left(p_{H}-p_{L}\right) R_{2}$ unit of money loans from the central bank, which is equal to early entrepreneurs' demand for buying the consumption goods from late entrepreneurs less the collateral;

2. Banks repay $\gamma\left(1-\alpha_{H}\right)\left(1-p_{L}\right) R_{2}$ to early entrepreneurs;

3. Early entrepreneurs purchase $\gamma\left(1-\alpha_{H}\right)\left(1-p_{L}\right) R_{2}$ consumption goods from late entrepreneurs;

4. Late entrepreneurs repay their loans, $\gamma\left(1-\alpha_{H}\right)\left(1-p_{L}\right) R_{2}$, to banks.

Since at that stage return of the collateral is realized, banks

4.5 Repay $\gamma\left(1-\alpha_{H}\right)\left(p_{H}-p_{L}\right) R_{2}$ inter-date loans to the central bank.

And in the last step 5, the intraday loan is repaid, too.

In the following proposition, we show that the constrained efficient allocation can be replicated in the decentralized monetary economy:

Proposition 3 In the decentralized monetary economy, with a central bank as monetary authority providing both interday and intraday loans to the banking sector, the constrained efficient solution can be replicated such that

1. At $t=0$ all banks invest a share $\alpha^{*}=\alpha_{H}=\frac{\gamma-p_{H}}{\gamma-p_{H}+(1-\gamma) \frac{R_{1}}{R_{2}}}$ on the safe projects, and promise the depositors $d_{0}=\gamma\left[\alpha^{*} R_{1}+\left(1-\alpha^{*}\right) R_{2}\right]$ nominal return at $t=1$ for each unit of deposit;

2. If it is in the good state at $t=1$, the depositors receive $d_{0}=\alpha^{*} R_{1}+\left(1-\alpha^{*}\right) p_{H} R_{2}$ consumption, and the price level is $P_{g}=1$;

3. If it is in the bad state at $t=1$, the depositors receive $d_{0}=\gamma\left[\alpha^{*} R_{1}+\left(1-\alpha^{*}\right) R_{2}\right]$ nominal repayment and purchase consumption good at the price $P_{b}=\frac{d_{0}}{\alpha^{*} R_{1}+\left(1-\alpha^{*}\right) p_{L} R_{2}}>P_{g}=1$. The consumption of depositors is $1<\alpha^{*} R_{1}+\left(1-\alpha^{*}\right) p_{L} R_{2}<d_{0}$, but there is no bank run;

4. Banks get access to the central bank's interday loan facility only in the bad state at $t=1$ : Banks get $\gamma\left(1-\alpha^{*}\right)\left(p_{H}-p_{L}\right) R_{2}$ liquidity through interday loan, using the same amount of late projects as collateral. The interday loan will be repaid at $t=2$, when late projects return;

5. The central bank's policy rate is above $\frac{\left(1-p_{H}\right) R_{2}}{\alpha^{*}\left(R_{1}-R_{2}\right)+\left(1-p_{H}\right) R_{2}}>1$ throughout the entire time horizon, but should be lowered to 1 at $t=1$ when the bad state is revealed.

Proof: See Appendix.

In the good state, banks holding a share $\alpha_{H}$ of liquid assets will be able to make nominal repayment $d_{0}$ to the depositors, by borrowing from early entrepreneurs against their illiquid assets. In this case, banks need intraday loans from the central bank only for transaction purpose, and depositors' real consumption is $d_{0}$, too. In the bad state, by borrowing from early entrepreneurs, banks will not be able to fulfill $d_{0}$ nominal repayment to depositors, since in that state the aggregate early output - hence the money obtained from intraday loans - is lower than $d_{0}$. However, banks now have more delayed projects which can be used as collateral for interday loans. Therefore, they can get additional funding 
from the central bank's liquidity line and so meet the depositors' demand for nominal repayment. In this case, depositors' real consumption will now be lower than $d_{0}$ with the price level rising above 1 , but depositors have no longer incentive to run on the banks. In other words, the central bank's interday loans allow banks to fulfill depositors' demand for nominal repayment in both states, while the price level adjusts to make depositors' real consumption contingent on the states. This eliminates the fragility arising from the fixed deposit contracts and improves social welfare.

\section{Market equilibrium in the monetary economy and systemic liquidity risk}

The key mechanism to replicate the constraint efficient solution hinges on the central bank's interest rate policy, which works through the liquidity facility. The policy rate should be so high in the normal state that banks are induced to implement the first best equilibrium, while it should be low enough in the crisis state that banks are guaranteed for sufficient liquidity through the central bank's liquidity facility.

However, the central bank's commitment to high policy rate in the normal state, which intends to deter banks' incentive of over-investing in illiquid assets, is an incredible threat. Since the social cost of bank failure is too high, it is ex post optimal for the central bank to bail out the illiquid banks even in the normal state. Such time-inconsistency problem is characterized by the following proposition:

Proposition 4 In the decentralized monetary economy, with a central bank as monetary authority providing both interday and intraday loans to the banking sector, the market equilibrium is featured by

1. At $t=0$ all banks invest a share $\alpha=0$ on the safe projects, and promise the depositors $d_{0}=\gamma R_{2}$ nominal return at $t=1$ for each unit of deposit;

2. The central bank's policy rate is 1 at $t=1$, no matter what state the economy is in;

3. If it is in the good state at $t=1$, the depositors receive $d_{0}=p_{H} R_{2}$ consumption, and the price level is $P_{g}^{\prime}=\frac{\gamma}{p_{H}}>P_{g}$;

4. If it is in the bad state at $t=1$, the depositors receive $d_{0}=p_{L} R_{2}$ consumption, and the price level is $P_{b}^{\prime}=\frac{\gamma}{p_{L}}>P_{b}$;

5. Banks get access to the central bank's interday loan facility in both states at $t=1$ : Banks get $\left(\gamma-p_{s}\right) R_{2}(s=\{H, L\})$ liquidity through interday loan, using the same amount of late projects as collateral. The interday loan will be repaid at $t=2$, when late projects return.

Proof: See Appendix.

Proposition 4 says that constrained efficient solution is bound to break down in the monetary economy, when a central bank conducts active monetary policy, using short-term interest rate as policy instrument and providing liquidity to the banking sector via interday loans. This is due to the moral hazard arising from central bank's time-inconsistent policy: Suppose that one bank $i$ deviates from the constrained efficient solution by setting $\tilde{\alpha}<\alpha^{*}$ and $\tilde{d}_{0}=\gamma\left[\tilde{\alpha} R_{1}+(1-\tilde{\alpha}) R_{2}\right]$ at $t=0$, then this bank will suffer from liquidity shortage at $t=\frac{1}{2}$ even in the normal state. Although in the normal state the central bank would like to commit to set its policy rate well above 1, it is now ex post optimal for the central bank to cut its rate to 1 to avoid bank's failure. However, this means that the total nominal payoff that bank $i$ can get is $\tilde{d}_{0}=\gamma\left[\tilde{\alpha} R_{1}+(1-\tilde{\alpha}) R_{2}\right]>\gamma\left[\alpha^{*} R_{1}+\left(1-\alpha^{*}\right) R_{2}\right]=d_{0}^{*}$, i.e., this deviator can offer higher nominal return to its depositors and outbid all its rivals. Knowing this, no 
bank will have an incentive to hold liquid assets at $t=0$ and the central bank will be forced to choose low interest rates in both states. Although depositors get higher nominal return, their real consumption is below the constrained efficient solution since too many projects are postponed to $t=2$. The economy is trapped in the inferior equilibrium. In the next section, we show that the same result holds in the long-run equilibrium.

\section{Systemic liquidity risk in the long-run equilibrium}

Now suppose that the monetary model extends to multiple periods, $t \in\{0, \ldots, T\}$. The settings remain almost the same, except that depositors and entrepreneurs come from overlapping generations, while banks are infinitely-lived. Assume that

(1) There is a continuum of depositors born in each period $t$, call them generation $t$ depositors. Each depositor lives for up to two dates - "young” and "old": she deposits her endowment in a bank when she is young, and she consumes when she is old. There is no population growth;

(2) There is a continuum of entrepreneurs born in each period $t$ - call them generation $t$ entrepreneurs - each running either a safe or a risky project. Each entrepreneur lives for up to three periods - "young”, "middle age” and “old”: she works on one project (call it project $t$ ) when she is young, then consumes the proceeds later;

(3) There is a finite number $N$ of active banks engaged in Bertrand competition in the deposit market by offering fixed nominal deposit contracts $d_{0, t}$ to generation $t$ depositors. When a bank experiences a run, it can be restructured and restart its business in the next period.

At each intermediate period $t+\frac{1}{2}$, the state of the world $p_{t} \in\left\{p_{H}, p_{L}\right\}$ for date $t+1$ is revealed. To focus on the illiquidity risk, we further assume that the crisis state is a low probability event, that is, $\pi \rightarrow 1$. With a central bank providing both medium of transaction and liquidity, the constrained efficiency can be implemented in the following way:

\section{At period 0}

Figure 6 shows the flows of money throughout the period:

1. Banks get 1 unit of intraday loans from the central bank, which is equal to the generation 0 entrepreneurs' demand for buying the endowments of generation 0 depositors. Central bank keeps its interday loan rate $r_{0}^{M}>\bar{r}=\frac{\left(1-p_{H}\right) R_{2}}{\alpha_{H}\left(R_{1}-R_{2}\right)+\left(1-p_{H}\right) R_{2}}>1$ throughout the period;

2. Banks issue loans to the entrepreneurs, a share of $\alpha_{0}=\alpha^{*}$ for the safe projects (short term loans), $1-\alpha_{0}$ for the risky projects (long term loans);

3. Entrepreneurs use the loans to purchase the depositors' endowments, as capital input to their projects;

4. Depositors deposit the money in banks, using the nominal demand deposit contracts;

5. At the end of the period, banks pay back the loans to the central bank. 


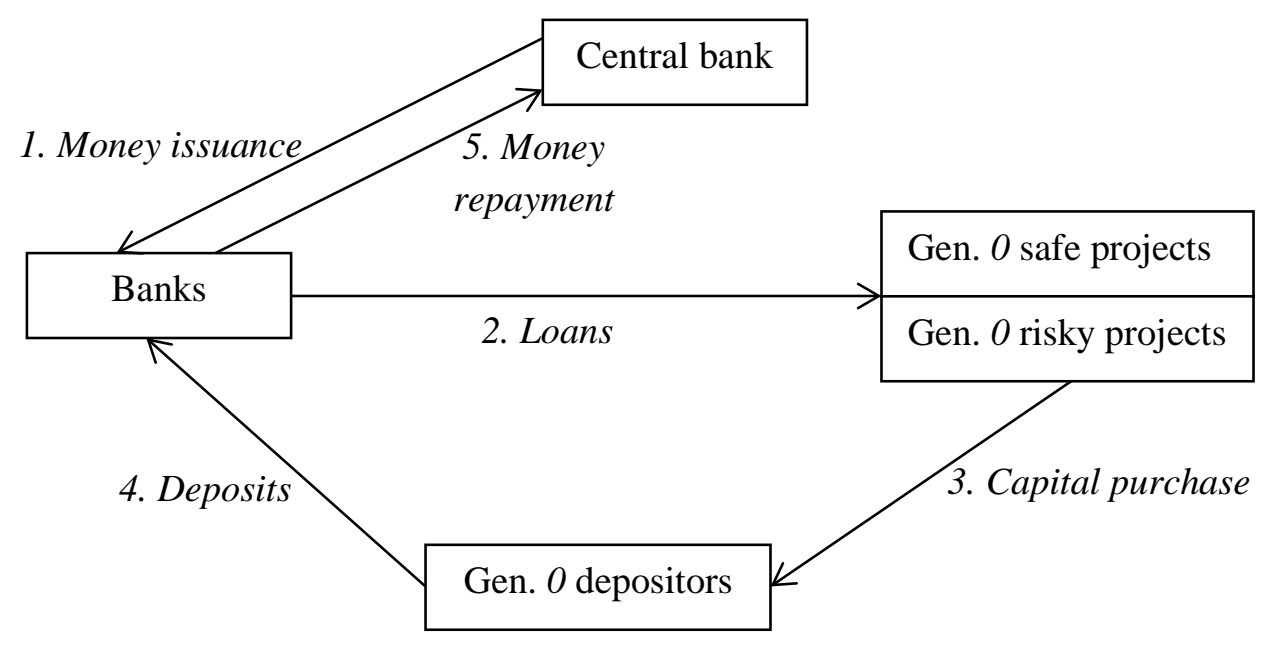

Figure 6 Monetizing the economy at $t=0$. The arrows show the direction of money flows, and the numbers indicate the timing of money flows.



Figure 7 Money flows at period $t=1$.

\section{At period 1}

Figure 7 shows the flows of money throughout the period:

1. Banks get $d_{0,0}$ unit of intraday loans from the central bank, which is equal to generation 0 depositors' demand for buying the consumption goods from early generation 0 entrepreneurs. Central bank keeps its interday loan rate $r_{0}^{M}>\bar{r}$ throughout the period;

2. Banks repay $d_{0,0}$ to generation 0 depositors;

3. Generation 0 depositors purchase $d_{0,0}=\alpha_{0} R_{1}+\left(1-\alpha_{0}\right) p_{0} R_{2}$ consumption goods from the early generation 0 entrepreneurs; 
4. Early generation 0 entrepreneurs repay their loans, $\gamma\left[\alpha_{0} R_{1}+\left(1-\alpha_{0}\right) p_{0} R_{2}\right]$, to banks, and

5. Deposit $(1-\gamma)\left[\alpha_{0} R_{1}+\left(1-\alpha_{0}\right) p_{0} R_{2}\right]$ in banks;

6. Banks issue loans to generation 1 entrepreneurs, a share of $\alpha_{1}=\alpha^{*}$ for the safe projects (short term loans), $1-\alpha_{1}$ for the risky projects (long term loans);

7. Generation 1 entrepreneurs use the loans to purchase generation 1 depositors' endowments, as capital input to their projects;

8. Generation 1 depositors deposit the money in banks, using the nominal demand deposit contracts;

9. At the end of the period, banks pay back the loans to the central bank.

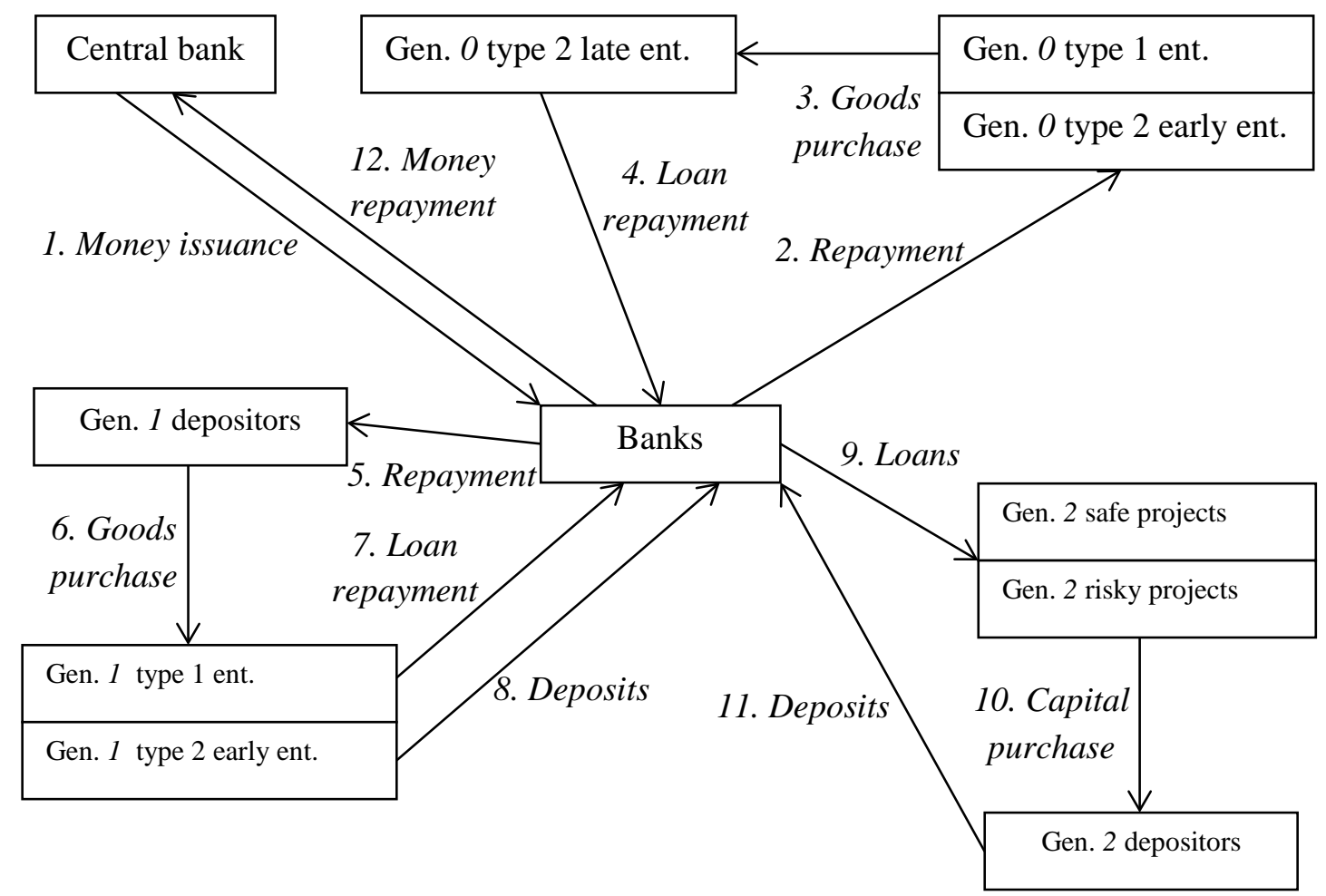

Figure 8 Money flows at period 2.

\section{At period 2}

Figure 8 shows the flows of money throughout the period:

1. Banks get $(1-\gamma)\left[\alpha_{0} R_{1}+\left(1-\alpha_{0}\right) p_{0} R_{2}\right]$ unit of intraday loans from the central bank, which is equal to early generation 0 entrepreneurs' demand for buying the consumption goods from late generation 0 entrepreneurs. Central bank keeps its interday loan rate $r_{0}^{M}>\bar{r}$ throughout the period;

2. Banks repay $(1-\gamma)\left[\alpha_{0} R_{1}+\left(1-\alpha_{0}\right) p_{0} R_{2}\right]$ to early generation 0 entrepreneurs;

3. Early generation 0 entrepreneurs purchase $(1-\gamma)\left[\alpha_{0} R_{1}+\left(1-\alpha_{0}\right) p_{0} R_{2}\right]=\gamma\left(1-\alpha_{0}\right)(1-$ $\left.p_{0}\right) R_{2}$ consumption goods from late generation 0 entrepreneurs;

4. Late generation 0 entrepreneurs repay their loans, $(1-\gamma)\left[\alpha_{0} R_{1}+\left(1-\alpha_{0}\right) p_{0} R_{2}\right]$, to banks; 
5. Banks get $d_{0,1}-\gamma\left(1-\alpha_{0}\right)\left(1-p_{0}\right) R_{2}$ more unit of money intraday loans from the central bank and repay $d_{0,1}$ to generation 1 depositors;

6. Generation 1 depositors purchase $d_{0,1}=\alpha_{1} R_{1}+\left(1-\alpha_{1}\right) p_{1} R_{2}$ consumption goods from the early generation 1 entrepreneurs;

7. Early generation 1 entrepreneurs repay their loans, $\gamma\left[\alpha_{1} R_{1}+\left(1-\alpha_{1}\right) p_{1} R_{2}\right]$, to banks, and

8. Deposit $(1-\gamma)\left[\alpha_{1} R_{1}+\left(1-\alpha_{1}\right) p_{1} R_{2}\right]$ in banks with gross interest rate 1 ;

9. Banks issue loans to generation 2 entrepreneurs, a share of $\alpha_{2}=\alpha^{*}$ for the safe projects (short term loans), $1-\alpha_{2}$ for the risky projects (long term loans);

10. Generation 2 entrepreneurs use the loans to purchase generation 2 depositors' endowments, as capital input to their projects;

11. Generation 2 depositors deposit the money in banks, using the nominal demand deposit contracts;

12. At the end of the period, banks pay back all the loans to the central bank.

For any period $2 \leq \tau \leq T$ after period 2 , the intraday money flows are similar as those in period 2 , as long as the economy is in the normal state, with $\alpha_{\tau}=\alpha^{*}$. However, it makes difference when the economy turns out to be in the crisis state. The difference starts from step 4, as Figure 9 shows:

4. Till this step, the money flows are the same as in Figure 8. However, when it comes to the repayment to generation $\tau-1$ depositors, banks can only get a total of $\alpha_{\tau-1} R_{1}+(1-$ $\left.\alpha_{\tau-1}\right) p_{L} R_{2}<d_{0, \tau-1}$ intraday loans from the central bank. Therefore

4.5 Banks get $\left(1-\alpha_{\tau-1}\right)\left(p_{H}-p_{L}\right) R_{2}$ liquidity through interday loans from the central bank using $\left(1-\alpha_{\tau-1}\right)\left(p_{H}-p_{L}\right) R_{2}$ long assets as collateral, and central bank reduces its policy rate (interday loan rate) $r_{\tau}^{M} \mid\left(p_{\tau-1}=p_{L}\right)=1$;

5. Banks repay $d_{0, \tau-1}$ to generation $\tau-1$ depositors;

6. Generation $\tau-1$ depositors purchase $\alpha_{\tau-1} R_{1}+\left(1-\alpha_{\tau-1}\right) p_{L} R_{2}$ consumption goods from the early generation $\tau-1$ entrepreneurs at a price $\frac{d_{0, \tau-1}}{\alpha_{\tau-1} R_{1}+\left(1-\alpha_{\tau-1}\right) p_{L} R_{2}}>1$;

7. Early generation $\tau-1$ entrepreneurs repay their loans, $\gamma\left[\alpha_{\tau-1} R_{1}+\left(1-\alpha_{\tau-1}\right) p_{L} R_{2}\right]$, to banks, and

8. Deposit $\gamma\left(1-\alpha_{\tau-1}\right)\left(1-p_{L}\right) R_{2}$ in banks with gross interest rate 1 ;

The rest are the same as in Figure 8, except that banks only repay $\alpha_{\tau-1} R_{1}+\left(1-\alpha_{\tau-1}\right) p_{L} R_{2}$ intradate loans to the central bank at the end of the period, retaining $\left(1-\alpha_{\tau-1}\right)\left(p_{H}-p_{L}\right) R_{2}$ as liabilities to the central bank backed by the collateral. 


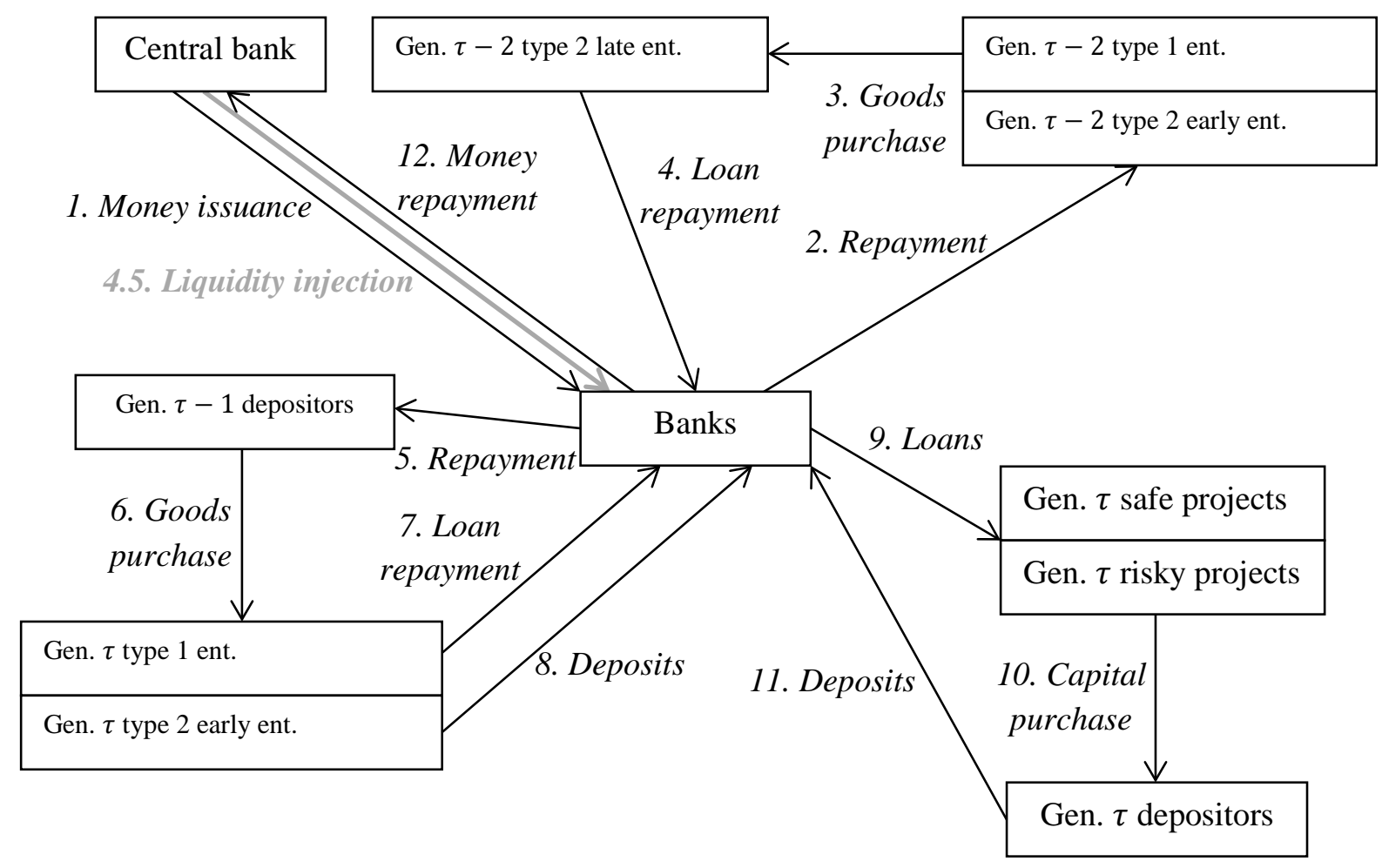

Figure 9 Money flows at any period $\tau$ in crisis state.

In the following period $\tau+1$, suppose that the economy is in the normal state, banks need to repay the inter-date loans when the assets in the collateral return, and central bank raises its interday loan rate to $r_{0}^{M}>\bar{r}$ throughout the period. As Figure 10 shows,

5. Banks get $\gamma\left(1-\alpha_{\tau-1}\right)\left(1-p_{L}\right) R_{2}-\left(1-\alpha_{\tau-1}\right)\left(p_{H}-p_{L}\right) R_{2}$ unit of intraday loans from the central bank, which is equal to early generation $\tau-1$ entrepreneurs' demand for buying the consumption goods from late generation $\tau-1$ entrepreneurs less the collateral;

6. Banks repay $\left(1-\alpha_{\tau-1}\right)\left(1-p_{L}\right) R_{2}$ to early generation $\tau-1$ entrepreneurs;

7. Early generation $\tau-1$ entrepreneurs purchase $\gamma\left(1-\alpha_{\tau-1}\right)\left(1-p_{L}\right) R_{2}$ consumption goods from late generation $t-1$ entrepreneurs;

8. Late generation $t-1$ entrepreneurs repay their loans, $\gamma\left(1-\alpha_{\tau-1}\right)\left(1-p_{L}\right) R_{2}$, to banks.

Since the collateral returns, banks

8.5 Repay $\left(1-\alpha_{\tau-1}\right)\left(p_{H}-p_{L}\right) R_{2}$ inter-date loans to the central bank.

The rest are the same as in Figure 8. 




Figure 10 Money flows at any period $\tau+1$ (in normal state) following a crisis state.

Proposition 5 With a central bank providing both medium of transaction and liquidity, the allocation implemented through Figure 6 to 10 is constrained efficient.

Proof: See Appendix.

In the normal state, central bank sets its policy rate so high that banks rely on the liquidity market instead of using central bank's liquidity facilities. As shown in the baseline case, if banks coordinate on choosing $\alpha_{H}$, the liquidity market in the next period will guarantee the constrained efficiency. When it is in the crisis state, central bank reduces its policy rate so that banks can obtain interday loans at the lowest cost. In this way, depositors nominal claims can be fulfilled and price in consumption goods market rises. Although in this case depositors' real return is lower than that in the normal state, they are still better off than receiving the poor return if they run on banks. Therefore, by making depositors' real return contingent on the state of the world, central banks' conducting monetary policy through its liquidity facilities avoids costly bank runs and achieves constrained efficiency.

But monetary policy also affects banks' behavior: central bank's commitment to provide cheap access to liquidity facilities under stress crowds out incentives of private liquidity provision. As a result, the constrained efficient allocation cannot be implemented as the market equilibrium.

To see this, suppose that at period $t$ the economy is in the normal state, while at $t+\frac{1}{2}$ it is revealed that the economy will be in the crisis state at period $t+1$ so that central bank needs to reduce its policy rate to $r_{t+1}^{M}=1$. At period $t+1$, banks make decision on their investment portfolios: (1) they can either invest $\alpha^{*}=\alpha_{H}$ as is suggested by the constrained efficient allocation, (2) or nothing in liquid assets, $\alpha^{*}=0$. Then at period $t+2$ (most likely, the economy is in the normal state), when 
central bank raises its policy rate to $r_{t+2}^{M}>\bar{r}$, if banks opted for (1), they will (be most likely to) survive since they can get obtain sufficient funding from liquidity market, while if banks opt for (2), they will become insolvent and experience runs since they cannot raise enough liquidity to fulfill depositors' claims. However, if central bank remains its policy rate as $r_{t+2}^{M}=1$, banks will survive under both (1) and (2) since they can access to cheap liquidity from central bank.

Ex post, central bank will be indifferent between $r_{t+2}^{M}>\bar{r}$ and $r_{t+2}^{M}=1$ under (1) since banks receive the same payoff, $\gamma\left[\alpha_{H} R_{1}+\left(1-\alpha_{H}\right) R_{2}\right]$; under (2), it will prefer $r_{t+2}^{M}=1$ to $r_{t+2}^{M}>\bar{r}$ to avoid costly bank runs. However, knowing this, banks will strictly prefer $\alpha^{*}=0$ to $\alpha^{*}=\alpha_{H}$ at period $t+1$, since their payoff is strictly higher, $\gamma R_{2}>\gamma\left[\alpha_{H} R_{1}+\left(1-\alpha_{H}\right) R_{2}\right]$. Therefore, in the dynamic consistent market equilibrium, banks choose $\alpha^{*}=0$ and central bank remains $r_{t}^{M}=1$. By backward induction, this applies for all $t \in\{0, \ldots, T\}$.

Notice that in such equilibrium, although depositors receive higher nominal return $\gamma R_{2}>$ $\gamma\left[\alpha_{H} R_{1}+\left(1-\alpha_{H}\right) R_{2}\right]$, their real consumption $\gamma p_{t} R_{2}$ is lower, $\gamma p_{t} R_{2}<\alpha_{H} R_{1}+\left(1-\alpha_{H}\right) p_{t} R_{2}$. This is due to the fact that all resources are invested in the illiquid assets so that the early return for depositors is too low. That is, depositors are worse off in the dynamic consistent market equilibrium.

In summary, the dynamic consistent market equilibrium can be characterized in the following proposition:

Proposition 6 With a central bank providing both medium of transaction and liquidity, the unique dynamic consistent market equilibrium is characterized by

(1) Banks choose $\alpha_{t}=0$ and offer nominal deposit contracts $d_{0 t}=\gamma R_{2}$ to depositors, $\forall t \in$ $\{0, \ldots, T\}$;

(2) Central bank sets $r_{t}^{M}=1$, irrespective to the signals observed at $t-\frac{1}{2}$;

(3) Depositors become worse off than they are under the constrained efficient allocation.

Proof: See Appendix.

It can be also easily seen that the same conclusion holds even if the time horizon is infinite:

Corollary The dynamic consistent market equilibrium remains the same when $T \rightarrow+\infty$.

\section{Discussion}

In this section, we discuss two extensions of the model. First, instead of aggregate liquidity shocks, we assume that liquidity shocks are idiosyncratic to the banks. We show in this case, the market will reach constrained efficient allocation even in the real economy, while efficiency again breaks down in the monetary economy. Then we discuss adequte mechanism design to implement constrained efficiency in the monetary economy. We show that monetary policy rule fails to work due to time inconsistency problem, and ex ante liquidity requirement is needed to implement the constrained efficient outcome.

\subsection{Idiosyncratic liquidity shocks}

Instead of aggregate liquidity shocks to all banks, suppose that each bank experiences an i.i.d. shock $p_{i}$ $(i \in\{1, \ldots, N\})$ which is randomly drawn from a probabilistic distribution $f\left(p_{i}\right)$ with support $\left[p_{L}, p_{H}\right]$ 
$\left(0<p_{L}<p_{H}<\gamma<1\right)$. Further, we assume that the number of banks $N$ is large enough so that the Law of Large Numbers holds.

When liquidity shocks are idiosyncratic, the market equilibrium will be constrained efficient in the real economy. At $t=0$ banks invest $\alpha_{E[p]}$ in liquid assets, based on the expected value of $p$; as shock to each bank is revealed, banks' liquidity problem will be solved by liquidity market: the demand for liquidity (from those banks with liquidity shortages $p_{i}<E[p]$ ) will be met by the supply of liquidity (from those banks with liquidity surplus $p_{i}>E[p]$ ). Such equilibrium is summarized by the following proposition:

Proposition 7 The market equilibrium in the real economy is constrained efficient, featured by

(1) At $t=0$ each bank invests a share $\alpha_{E[p]}=\frac{\gamma-E[p]}{\gamma-E[p]+(1-\gamma) \frac{R_{1}}{R_{2}}}$ in the safe assets, and the depositors' expected return at $t=1$ is $d_{0}=\gamma\left[\alpha_{E[p]} R_{1}+\left(1-\alpha_{E[p]}\right) R_{2}\right]$;

(2) Liquidity market at $t=1$ will redistribute liquidity among banks with liquidity surplus and banks with liquidity shortages, and the market is cleared at interest rate $r=1$. All banks are able to fulfill depositors' claims, and there is no bank run.

Proof See Appendix.

Proposition 7 says that as long as the ex ante symmetric banks hold a share $\alpha$ of liquid assets, $-\alpha$ being chosen based on their expectation on liquidity shock $p$ - after $p$ gets revealed for all the banks, there will be banks with liquidity shortage (more delayed risky projects than they expected) and banks with liquidity surplus (less delayed risky projects than they expected). The market mechanism will ensure that the former can borrow from the early entrepreneurs of the latter, so that depositors of all the banks can get fully repaid at $t=1$.

However, this conclusion will no longer hold in the nominal economy, with a central bank injecting money into the economy via intraday and interday loans. Since there is only illiquidity risk, at $t=1$ the banks can always use the risky assets as good collateral to get liquidity through the central bank's interday loans. On the other hand, banks with liquidity shortage have to borrow from the central bank at $t=1$. It is always ex post optimal for the central bank to lower the interest rate of interday loans to reduce the likelihood of bank failure. Knowing this, the banks will minimize their liquid assets holding at $t=0$, aiming to maximize liquidity borrowed through interday loans at $t=1$, - hence the nominal return at $t=1$ - and the central bank will be forced to cut the interest rate down to $r=1$ to avoid bank runs. So the central bank's commitment to providing standing liquidity facilities crowds out the incentive of private liquidity provision. Although in nominal terms depositors get $d_{0}=\gamma R_{2}$ irrespective to the banks' idiosyncratic shocks, higher than that in the constrained efficient solution, their real consumption is $E[p] R_{2}$ which is below the constrained efficient solution. Depositors are worse off.

\subsection{Liquidity requirement and monetary policy}

In the monetary economy, constrained efficiency breaks down because the central bank's commitment to providing interday loans against good collateral encourages banks to take excessive illiquidity risks. To restore the constrained efficiency, one may suggest that the central bank can use monetary policy to correct banks' incentives (such as Freixas, Martin and Skeie, 2011), i.e., when the good state is observed, the policy rate should be prohibitively high so that banks need to borrow from liquidity market; while when the bad state is observed, the policy rate should be low enough that banks can 
survive through the central bank's liquidity line. Knowing this, banks will have the incentive to hold liquid assets so that market mechanism works to allocate liquidity in the good state, and costly bank runs will be eliminated in the bad state since banks can access central bank's liquidity facilities at low cost.

Unfortunately, such monetary policy rule fails to work in our dynamic setup since the rule itself is not credible: If banks do not hold enough liquid assets at $t=0$, ex post it is always optimal for the central bank to cut down policy rate at $t=1$ to avoid costly bank run. Knowing this, banks will not invest on liquid assets at $t=0$ and the central bank will be forced to set policy rate to 1 despite the state of the economy. The time inconsistency problem makes the proposed monetary policy fail to save the economy out of the inferior equilibrium.

To avoid supporting banks with excessive investment on illiquid assets, one might suggest the central bank should commit to provide interday loans only to those banks who hold sufficient liquid assets, i.e., $\alpha \geq \alpha^{*}$ in our model. However, such policy suffers from the same time inconsistency problem: If one bank doesn't hold enough liquid assets, $\alpha<\alpha^{*}$, at $t=0$, it is still ex post optimal for the central bank to allow the bank to access interday loans and avoid costly liquidation from any bank runs. Therefore, there will be no incentive for banks to hold liquidity in the first place.

Therefore, rather than relying on implausible commitment mechanisms, the solution to fix the time inconstancy problem and restore constrained efficiency in the monetary economy is to combine ex ante liquidity requirement and ex post liquidity facilities. In the first place, banks should be obliged to meet a certain requirement of holding liquid assets (such as Liquidity Coverage Ratio defined in Basel III) in the normal time, and when there is a systemic liquidity shortage, central bank commits to providing liquidity through interday loans and eliminates bank runs. This deters the moral hazard that banks are engaged in investing on excessive illiquid assets, raises despositors' expected real return and restores constrained efficiency.

\section{Conclusion}

Our paper developed a framework for analyzing the roles of money in banking, both as medium for transaction and as bank liquidity. In the model, banks provide maturity transformation service to depositors. With fixed deposit contracts and aggregate liquidity risk, the fragile structure of banking triggers bank run in the bad state, leading to socially costly liquidation.

Ideally, in a monetary economy with nominal deposit contracts, a central bank conducting active monetary policy can eliminate such costly liquidation and replicate the first best solution. Money is issued by the central bank through (1) intraday loans to the bank, as a medium facilitating transaction, and (2) interday loans to banks, or standing liquidity facilities, to accommodate their demand for liquidity, using illiquid long assets as collateral. In good times, banks can borrow from the liquidity market to meet depositors' demand; while in bad times when banks suffer from liquidity shortage, central bank will inject liquidity to the market through liquidity facilities, making sure banks can still fulfill their nominal deposit contracts. Central bank's policy rate should be high in good times to encourage the efficient market outcome, while it should be low in bad times to avoid runs.

Unfortunately, such a scheme cannot be equilibrium market outcome. Absent liquidity regulation, banks always have incentives to invest excessively on the illiquid assets and obtain liquidity from the central bank to maximize depositors' nominal return. Banks are more likely to have liquidity shortage even in good times. So the central bank will be forced to cut down its policy rate to prevent bank 
failure. As a result, the economy will end up in an inferior equilibrium: banks overinvest in illiquid assets, the central bank has to keep policy rate low, and depositors are worse off from lower real consumption.

We show that using interest rate rules to deter banks' excessive risk taking is not credible for implementing the constrained efficient allocation, because of a time inconsistency problem: Once banks engage in excessive liquidity risks ex ante, it is always ex post optimal for the central bank to cut down interest rate. An additional instrument, such as imposing liquidity coverage requirement ex ante, is needed to restore efficiency in the monetary equilibrium.

\section{Appendix}

\section{A. Proof of Proposition 1}

The proposition is proved by construction. First, suppose that there is no aggregate risk and $p_{s}$ ( $s \in\{H, L\}$ ) is known at $t=0$, the social planner's problem is to maximize depositors' return by choosing $\alpha_{s}$ :

$$
\max _{\alpha_{s} \in[0,1]} \gamma\left\{\alpha_{s} R_{1}+\left(1-\alpha_{s}\right)\left[p_{s} R_{2}+\frac{\left(1-p_{s}\right) R_{2}}{r_{s}}\right]\right\}
$$

with market clearing condition

$$
r_{s}(1-\gamma)\left[\alpha_{s} R_{1}+\left(1-\alpha_{s}\right) p_{s} R_{2}\right]=\gamma\left(1-\alpha_{s}\right)\left(1-p_{s}\right) R_{2}
$$

and incentive compatibility constraint for entrepreneurs $r_{s} \geq 1$.

The solution is $\alpha_{s}=\frac{\gamma-p_{S}}{\gamma-p_{S}+(1-\gamma) \frac{R_{1}}{R_{2}}}$.

With aggregate risk, the incentive compatibility constraint for entrepreneurs still holds, implying that depositors' expected return at $t=0$ is

$$
\begin{aligned}
E[R(\alpha)]=\pi \min \left\{\alpha R_{1}+(1-\alpha) p_{H} R_{2}, \gamma\left[\alpha R_{1}+(1-\alpha) R_{2}\right]\right\} & \\
& +(1-\pi) \min \left\{\alpha R_{1}+(1-\alpha) p_{L} R_{2}, \gamma\left[\alpha R_{1}+(1-\alpha) R_{2}\right]\right\}, \forall \alpha \in[0,1]
\end{aligned}
$$

When $\pi$ is sufficiently large $\left(\pi \in\left(\frac{\gamma E\left[R_{L}\right]-c}{\gamma E\left[R_{H}\right]-c}, 1\right)\right.$ ), depositors' expected return under different $\alpha$ is

(1) If $\alpha \in\left[\alpha_{L}, 1\right]$, depositors' expected return is $E[R(\alpha)]=\gamma\left[\alpha R_{1}+(1-\alpha) R_{2}\right]<$ $\pi \gamma\left[\alpha_{H} R_{1}+\left(1-\alpha_{H}\right) R_{2}\right]+(1-\pi) \gamma\left[\alpha_{L} R_{1}+\left(1-\alpha_{L}\right) R_{2}\right]=E\left[R\left(\alpha_{H}\right)\right]$

(2) If $\alpha \in\left[0, \alpha_{H}\right)$, depositors' expected return is $E[R(\alpha)]=\pi\left[\alpha R_{1}+(1-\alpha) p_{H} R_{2}\right]+$ $(1-\pi)\left[\alpha R_{1}+(1-\alpha) p_{L} R_{2}\right]<\pi\left[\alpha_{H} R_{1}+\left(1-\alpha_{H}\right) p_{H} R_{2}\right]+(1-\pi)\left[\alpha_{H} R_{1}+(1-\right.$ $\left.\left.\alpha_{H}\right) p_{L} R_{2}\right]=E\left[R\left(\alpha_{H}\right)\right]$

(3) If $\alpha \in\left(\alpha_{H}, \alpha_{L}\right)$, depositors' expected return is $E[R(\alpha)]=\pi \gamma\left[\alpha R_{1}+(1-\alpha) R_{2}\right]+$ $(1-\pi)\left[\alpha R_{1}+(1-\alpha) p_{L} R_{2}\right]$. When $\pi$ is sufficiently large, $E[R(\alpha)]<\pi\left[\alpha_{H} R_{1}+\right.$ $\left.\left(1-\alpha_{H}\right) p_{H} R_{2}\right]+(1-\pi)\left[\alpha_{H} R_{1}+\left(1-\alpha_{H}\right) p_{L} R_{2}\right]=E\left[R\left(\alpha_{H}\right)\right]$.

Therefore, when $\pi$ is sufficiently large, choosing $\alpha_{H}$ maximizes depositors' expected return. 


\section{B. Proof of Proposition 2}

To show that the allocation is the market equilibrium in real economy, we need to show that the allocation is feasible and it is not profitable for any bank to deviate unilaterally.

If all banks choose $\alpha^{*}=\alpha_{H}$, when $p_{H}$ is revealed, depositors will get maximized return, $d_{0}^{*}=\gamma E\left[R_{H}\right]$, and this is exactly the solution to the planner's problem. However, when $p_{L}$ is revealed at $t=\frac{1}{2}$, banks can at most collect $\alpha_{H} R_{1}+\left(1-\alpha_{H}\right) p_{L} R_{2}<d_{0}^{*}$ from early entrepreneurs and liquidity market at $t=1$. This triggers bank run at $t=\frac{1}{2}$, forcing banks to liquidate both safe and risky projects for an inferior return $c$. Therefore, depositors' expected return at $t=0$ is $\gamma \pi E\left[R_{H}\right]+(1-\pi) c<$ $\gamma \pi E\left[R_{H}\right]+(1-\pi)\left[\alpha_{H} R_{1}+\left(1-\alpha_{H}\right) p_{L} R_{2}\right]=E\left[R\left(\alpha_{H}\right)\right]$, inferior to the planner's solution.

Suppose one bank $i$ chooses $\alpha_{i} \neq \alpha_{H}$ :

(1) If $\alpha_{i}<\alpha_{H}$, when $p_{H}$ is revealed, the interest rate in liquidity market at $t=1$ is determined by

$$
\begin{gathered}
r^{\prime}\left\{(1-\gamma)\left[\alpha_{i} R_{1}+\left(1-\alpha_{i}\right) p_{H} R_{2}\right]+(N-1)(1-\gamma)\left[\alpha_{H} R_{1}+\left(1-\alpha_{H}\right) p_{H} R_{2}\right]\right\} \\
=\gamma\left(1-\alpha_{i}\right)\left(1-p_{H}\right) R_{2}+(N-1) \gamma\left(1-\alpha_{H}\right)\left(1-p_{H}\right) R_{2} .
\end{gathered}
$$

Remember that in the planner's problem, equilibrium interest rate is determined by

$$
r_{H}(1-\gamma)\left[\alpha_{H} R_{1}+\left(1-\alpha_{H}\right) p_{H} R_{2}\right]=\gamma\left(1-\alpha_{H}\right)\left(1-p_{H}\right) R_{2},
$$

and $r_{H}=1$. Therefore, $r^{\prime}>1$. For the non-deviators, their return at $t=1$ becomes

$$
\gamma\left\{\alpha_{H} R_{1}+\left(1-\alpha_{H}\right)\left[p_{H} R_{2}+\frac{\left(1-p_{H}\right) R_{2}}{r^{\prime}}\right]\right\}<d_{0}^{*}
$$

When $p_{L}$ is revealed, both deviator and non-deviators will experience runs.

Knowing that non-deviators will not even be able to meet the contracted $d_{0}^{*}$ at $t=1$, the depositors will only deposit at bank $i$ at $t=0$. If so, the deposit return that bank $i$ can offer is

$$
d_{0 i}=\alpha_{i} R_{1}+\left(1-\alpha_{i}\right) p_{H} R_{2}<d_{0}^{*}
$$

implying that the deviator becomes worse off;

(2) If $\alpha_{i}>\alpha_{H}$, when $p_{H}$ is revealed, the aggregate liquidity supply at $t=1$ exceeds aggregate liquidity demand because

$$
\begin{aligned}
&(1-\gamma)\left[\alpha_{i} R_{1}+\right.\left.\left(1-\alpha_{i}\right) p_{H} R_{2}\right]+(N-1)(1-\gamma)\left[\alpha_{H} R_{1}+\left(1-\alpha_{H}\right) p_{H} R_{2}\right] \\
&>N(1-\gamma)\left[\alpha_{H} R_{1}+\left(1-\alpha_{H}\right) p_{H} R_{2}\right]=N \gamma\left(1-\alpha_{H}\right)\left(1-p_{H}\right) R_{2},
\end{aligned}
$$

Implying that the liquidity market interest rate remains at $r=1$ and non-deviators are able to meet $d_{0}^{*}$ at $t=1$. However, the deviator's return at $t=1$ is

$$
d_{0 i}=\gamma\left[\alpha_{i} R_{1}+\left(1-\alpha_{i}\right) R_{2}\right]<d_{0}^{*} .
$$

When $p_{L}$ is revealed, non-deviator banks experience liquidity shortages and bid up the liquidity market interest rate. As a result, even if the deviator invests more on liquid assets, it cannot meet the deposit contract either. Therefore, both deviator and non-deviators will experience runs.

Since the expected return from non-deviator banks is higher than that from the deviator, implying that the deviator will not get any deposit at $t=0$ and is hence worse off.

Therefore the suggested allocation is indeed the market equilibrium in real economy. 


\section{Proof of Proposition 3}

By investing a share $\alpha^{*}=\alpha_{H}=\frac{\gamma-p_{H}}{\gamma-p_{H}+(1-\gamma) \frac{R_{1}}{R_{2}}}$ at $t=0$ on the safe projects, at $t=1$

(1) If it is in the good state, banks collect $\gamma\left[\alpha_{H} R_{1}+\left(1-\alpha_{H}\right) p_{H} R_{2}\right]$ real return from early entrepreneurs. Using the late projects $\left(1-\alpha_{H}\right)\left(1-p_{H}\right) R_{2}=(1-\gamma)\left[\alpha_{H} R_{1}+(1-\right.$ $\left.\left.\alpha_{H}\right) p_{H} R_{2}\right]$ as collateral, the banks are able to borrow $(1-\gamma)\left[\alpha_{H} R_{1}+\left(1-\alpha_{H}\right) p_{H} R_{2}\right]$ from the early entrepreneurs at the interest rate $r_{g}=1$. The central bank's aggregate supply of money to the banks through intraday loans is thus $M_{g}=\gamma\left[\alpha_{H} R_{1}+\left(1-\alpha_{H}\right) p_{H} R_{2}\right]+$ $(1-\gamma)\left[\alpha_{H} R_{1}+\left(1-\alpha_{H}\right) p_{H} R_{2}\right]=\alpha_{H} R_{1}+\left(1-\alpha_{H}\right) p_{H} R_{2}=\gamma\left[\alpha_{H} R_{1}+\left(1-\alpha_{H}\right) R_{2}\right]=d_{0}$, the same as the depositors' nominal return. On the other hand, the aggregate output at $t=1$ is $Y_{g}=\alpha_{H} R_{1}+\left(1-\alpha_{H}\right) p_{H} R_{2}$, the aggregate demand for money in goods transaction $P_{g} Y_{g}=$ $M_{g}$ implies that the price level is $P_{g}=1$;

(2) If it is in the bad state, banks collect $\gamma\left[\alpha_{H} R_{1}+\left(1-\alpha_{H}\right) p_{L} R_{2}\right]$ real return from early entrepreneurs. Using $(1-\gamma)\left[\alpha_{H} R_{1}+\left(1-\alpha_{H}\right) p_{L} R_{2}\right]$ late projects as collateral, the banks are able to borrow $(1-\gamma)\left[\alpha_{H} R_{1}+\left(1-\alpha_{H}\right) p_{L} R_{2}\right]$ from the early entrepreneurs at the interest rate $r_{b}=1$. The central bank's aggregate supply of money to the banks through intraday loans is thus $\gamma\left[\alpha_{H} R_{1}+\left(1-\alpha_{H}\right) p_{L} R_{2}\right]+(1-\gamma)\left[\alpha_{H} R_{1}+\left(1-\alpha_{H}\right) p_{L} R_{2}\right]=\alpha_{H} R_{1}+$ $\left(1-\alpha_{H}\right) p_{L} R_{2}$. The banks can further borrow from the central bank at $r^{M}=1$ through interday loans, using the rest of late projects $\gamma\left(1-\alpha_{H}\right)\left(p_{H}-p_{L}\right) R_{2}$ as collateral. In the end, the depositors' nominal return, or aggregate money supply in the economy, is $M_{b}=$ $\gamma\left[\alpha_{H} R_{1}+\left(1-\alpha_{H}\right) p_{L} R_{2}\right]+(1-\gamma)\left[\alpha_{H} R_{1}+\left(1-\alpha_{H}\right) p_{L} R_{2}\right]+\gamma\left(1-\alpha_{H}\right)\left(p_{H}-p_{L}\right) R_{2}=$ $\alpha_{H} R_{1}+\left(1-\alpha_{H}\right) p_{H} R_{2}=\gamma\left[\alpha_{H} R_{1}+\left(1-\alpha_{H}\right) R_{2}\right]=d_{0}$, the same as that is promised in the deposit contracts. On the other hand, the aggregate output at $t=1$ is now $Y_{b}=\alpha_{H} R_{1}+$ $\left(1-\alpha_{H}\right) p_{L} R_{2}$, the aggregate demand for money in goods transaction $P_{b} Y_{b}=M_{b}$ implies that the price level is $P_{b}=\frac{d_{0}}{\alpha_{H} R_{1}+\left(1-\alpha_{H}\right) p_{L} R_{2}}=\frac{\alpha_{H} R_{1}+\left(1-\alpha_{H}\right) p_{H} R_{2}}{\alpha_{H} R_{1}+\left(1-\alpha_{H}\right) p_{L} R_{2}}>1$.

Furthermore, there will be no bank run in such decentralized monetary economy. In the good state, the depositors get $d_{0}$ nominal repayment and the same amount of real consumption, so there will be no incentive to run on the bank. In the bad state, the depositors get at most $\alpha_{H} R_{1}+\left(1-\alpha_{H}\right) p_{L} R_{2}<d_{0}$ consumption; however, if they run on the bank at $t=\frac{1}{2}$, they can only get $c<1<\alpha_{H} R_{1}+$ $\left(1-\alpha_{H}\right) p_{L} R_{2}$ real consumption. Therefore, they will prefer not to run on the bank and wait instead to get $d_{0}$ nominal repayment at $t=1$.

The banks' nominal repayment to depositors at $t=1$ is $d_{s}=\gamma\left\{\alpha_{H} R_{1}+\left(1-\alpha_{H}\right)\left[p_{s} R_{2}+\frac{\left(1-p_{s}\right) R_{2}}{r_{s}}\right]\right\}$, in which $r_{S}$ is the rate of the banks' borrowing from entrepreneurs and / or the central bank in the state $s \in\{H, L\}:$

(1) In the bad state, if the banks only borrow from early entrepreneurs, market clearing condition

$$
r_{L}(1-\gamma)\left[\alpha_{H} R_{1}+\left(1-\alpha_{H}\right) p_{L} R_{2}\right]=\gamma\left(1-\alpha_{H}\right)\left(1-p_{L}\right) R_{2}
$$

implies that $r_{L}>1$, hence $d_{L}<d_{0}$. However, if the central bank commits to setting $r^{M}=1$ for its interday loans so that banks can borrow from both early entrepreneurs and the central bank, depositors' nominal repayment will be $d_{L}=d_{0}$ since $r_{L}=r^{M}=1$. The constrained efficiency is achieved;

(2) In the good state, if the central bank's policy rate is $r_{g}^{M}=\frac{\left(1-p_{H}\right) R_{2}}{\alpha^{*}\left(R_{1}-R_{2}\right)+\left(1-p_{H}\right) R_{2}}>1$, the banks will only borrow from the early entrepreneurs at the rate $r_{H}=\frac{\gamma\left(1-\alpha_{H}\right)\left(1-p_{H}\right) R_{2}}{(1-\gamma)\left[\alpha_{H} R_{1}+\left(1-\alpha_{H}\right) p_{H} R_{2}\right]}=1$. 
The depositors' nominal repayment is therefore $d_{H}=d_{0}$ and the constrained efficiency is achieved.

\section{Proof of Proposition 4}

The proposition is proved by backward induction. The game consists of two subgames:

(1) At $t=1$, for the banks with strategic profile $\left(\alpha, d_{0}\right)$, the central bank needs to set its policy rate $r_{S}^{M}$ that maximizes the banks' return in the state $s \in\{H, L\}$, i.e.

$$
\max _{r_{S}^{M}} \gamma\left\{\alpha R_{1}+(1-\alpha)\left[p_{s} R_{2}+\frac{\left(1-p_{s}\right) R_{2}}{r_{s}}\right]\right\}
$$

in which $r_{s}=\min \left\{r_{s}^{0}, r_{S}^{M}\right\}$. The banks may borrow from the entrepreneurs at the rate $r_{s}^{0}$, which is determined by $r_{S}^{0}=\frac{\gamma(1-\alpha)\left(1-p_{s}\right) R_{2}}{(1-\gamma)\left[\alpha R_{1}+(1-\alpha) p_{s} R_{2}\right]}$, and $r_{S}^{0} \geq 1$ to allow entrepreneurs to participate. Obviously, the central bank's optimal policy rate is $r_{S}^{M}=1$ irrespective with the state;

(2) Known that $r_{S}=r_{S}^{M}=1$ at $t=1$, the banks' problem at $t=0$ is to choose the strategic profile $\left(\alpha, d_{0}\right)$ that maximizes depositors' nominal return, i.e.

$$
\max _{\left(\alpha, d_{0}\right)} d_{0}=\gamma\left\{\alpha R_{1}+(1-\alpha)\left[p_{s} R_{2}+\frac{\left(1-p_{s}\right) R_{2}}{r_{s}}\right]\right\}=\gamma\left\{\alpha R_{1}+(1-\alpha) R_{2}\right\} .
$$

Since $R_{2}>R_{1}$, it is optimal to set $\alpha=0$ and $d_{0}=\gamma R_{2}$.

As for the aggregate real output and price level,

(1) In the good state, banks collect $\gamma p_{H} R_{2}$ real return from early entrepreneurs. Using part of the late projects $(1-\gamma) p_{H} R_{2}$ as collateral, the banks are able to borrow $(1-\gamma) p_{H} R_{2}$ from the early entrepreneurs at the interest rate $r_{g}^{\prime}=1$. The central bank's aggregate supply of money to the banks through intraday loans is thus $\gamma p_{H} R_{2}+(1-\gamma) p_{H} R_{2}=p_{H} R_{2}$, The banks can further borrow from the central bank at $r^{M}=1$ through interday loans, using the rest of late projects $\gamma\left(1-p_{H}\right) R_{2}-(1-\gamma) p_{H} R_{2}=\left(\gamma-p_{H}\right) R_{2}$ as collateral. In the end, the depositors' nominal return, or aggregate money supply in the economy, is $M_{g}^{\prime}=\gamma p_{H} R_{2}+\gamma(1-$ $\left.p_{H}\right) R_{2}=\gamma R_{2}=d_{0}$, the same as that is promised in the deposit contracts. On the other hand, the aggregate output at $t=1$ is now $Y_{g}^{\prime}=p_{H} R_{2}$, the aggregate demand for money in goods transaction $P_{g}^{\prime} Y_{g}^{\prime}=M_{g}^{\prime}$ implies that the price level is $P_{g}^{\prime}=\frac{\gamma}{p_{H}}>P_{g}=1$;

(2) In the bad state, banks collect $\gamma p_{L} R_{2}$ real return from early entrepreneurs. Using part of the late projects $(1-\gamma) p_{L} R_{2}$ as collateral, the banks are able to borrow $(1-\gamma) p_{L} R_{2}$ from the early entrepreneurs at the interest rate $r^{\prime}{ }_{b}=1$. The central bank's aggregate supply of money to the banks through intraday loans is thus $\gamma p_{L} R_{2}+(1-\gamma) p_{L} R_{2}=p_{L} R_{2}$, The banks can further borrow from the central bank at $r^{M}=1$ through interday loans, using the rest of late projects $\gamma\left(1-p_{L}\right) R_{2}-(1-\gamma) p_{L} R_{2}=\left(\gamma-p_{L}\right) R_{2}$ as collateral. In the end, the depositors' nominal return, or aggregate money supply in the economy, is $M_{b}^{\prime}=\gamma p_{L} R_{2}+\gamma(1-$ $\left.p_{L}\right) R_{2}=\gamma R_{2}=d_{0}$, the same as that is promised in the deposit contracts. On the other hand, the aggregate output at $t=1$ is now $Y^{\prime}{ }_{b}=p_{L} R_{2}$, the aggregate demand for money in goods transaction $P^{\prime}{ }_{b} Y^{\prime}{ }_{b}=M^{\prime}{ }_{b}$ implies that the price level is $P^{\prime}{ }_{b}=\frac{\gamma}{p_{L}}=\frac{\gamma\left[\alpha_{H} R_{1}+\left(1-\alpha_{H}\right) R_{2}\right]}{p_{L}\left[\alpha_{H} R_{1}+\left(1-\alpha_{H}\right) R_{2}\right]}=$ $\frac{\alpha_{H} R_{1}+\left(1-\alpha_{H}\right) p_{H} R_{2}}{p_{L}\left[\alpha_{H} R_{1}+\left(1-\alpha_{H}\right) R_{2}\right]}>\frac{\alpha_{H} R_{1}+\left(1-\alpha_{H}\right) p_{H} R_{2}}{\alpha_{H} R_{1}+\left(1-\alpha_{H}\right) p_{L} R_{2}}=P_{b}$.

\section{E. Proof of Proposition 5}


Since the planner's problem is symmetric at any $t$, it is the same as the one in the static model characterized in section 2. The allocation implemented through Figure 6 to 10 is the same as in Proposition 1, therefore, it replicates the constrained efficient solution.

\section{F. Proof of Proposition 6}

The proposition is proved by backward induction. At any period $t$

(1) If the banks choose $\left(\alpha^{*}, d_{0}^{*}\right)$

a. If the central bank chooses $r_{t+1}^{M}=1$, banks' nominal return is $d_{0}^{*}$ despite the state at $t+1$

b. If the central bank chooses $r_{t+1}^{M}>1$, banks' nominal return is $d_{0}^{*}$ in the good state, while in the bad state the maximal nominal return is $\gamma\left[\alpha^{*} R_{1}+\left(1-\alpha^{*}\right) p_{L} R_{1}+\right.$ $\left.\frac{\left(1-\alpha^{*}\right)\left(1-p_{L}\right) R_{1}}{r_{t+1}^{M}}\right]<d_{0}^{*}$ so that banks will experience runs. Banks' expected nominal return at $t$ is therefore $\pi d_{0}^{*}+(1-\pi) c<d_{0}^{*}$;

(2) If the banks choose $\left(\tilde{\alpha}, \tilde{d}_{0}\right) \neq\left(\alpha^{*}, d_{0}^{*}\right)$

a. If the central bank chooses $r_{t+1}^{M}=1$, banks' nominal return is $\tilde{d}_{0}=\gamma\left[\tilde{\alpha} R_{1}+\right.$ $\left.(1-\tilde{\alpha}) R_{2}\right]$ which is maximized at $\tilde{\alpha}=0$. In this case, $\tilde{d}_{0}=\gamma R_{2}>d_{0}^{*}$;

b. If the central bank chooses $r_{t+1}^{M}>1$, banks' nominal return is, $\tilde{d}_{0}=\max \left\{\tilde{\alpha} R_{1}+\right.$ $\left.(1-\tilde{\alpha}) p R_{2}, \gamma\left[\tilde{\alpha} R_{1}+(1-\tilde{\alpha}) p R_{1}+\frac{(1-\tilde{\alpha})(1-p) R_{1}}{r_{t+1}^{M}}\right]\right\}<d_{0}^{*}$.

The unique subgame perfect equilibrium is that bankers choose $\alpha=0, d_{0}=\gamma R_{2}$ at $t$, and the central bank stays with $r_{t+1}^{M}=1$, irrespective of the signal observed at $t+1.5$. However, the real return the investors receive is $p R_{2}<d_{0}^{*}$.

\section{G. Proof of Proposition 7}

Under idiosyncratic liquidity shocks, the social planner's problem is to maximize depositors' expected return by choosing $\alpha_{i}$ for bank $i$ at $t=0$ :

$$
\max _{\alpha_{i} \in[0,1]} d_{0}=E_{0}\left[\gamma\left\{\alpha_{i} R_{1}+\left(1-\alpha_{i}\right)\left[p_{i} R_{2}+\frac{\left(1-p_{i}\right) R_{2}}{r}\right]\right\}\right],
$$

with market clearing condition

$$
r \sum_{i=1}^{N}(1-\gamma)\left[\alpha_{i} R_{1}+\left(1-\alpha_{i}\right) p_{i} R_{2}\right]=\sum_{i=1}^{N} \gamma\left(1-\alpha_{i}\right)\left(1-p_{i}\right) R_{2}
$$

and incentive compatibility constraint for entrepreneurs $r \geq 1$.

The solution is $\alpha_{i}=\frac{\gamma-E[p]}{\gamma-E[p]+(1-\gamma) \frac{R_{1}}{R_{2}}}, d_{0}=\gamma\left[\alpha_{E[p]} R_{1}+\left(1-\alpha_{E[p]}\right) R_{2}\right]$ and $r=1$.

In the market equilibrium, bank $i$ 's problem is to maximize its depositors' expected return by choosing $\alpha_{i}$ at $t=0$ : 


$$
\max _{\alpha_{i} \in[0,1]} d_{0}=E_{0}\left[\gamma\left\{\alpha_{i} R_{1}+\left(1-\alpha_{i}\right)\left[p_{i} R_{2}+\frac{\left(1-p_{i}\right) R_{2}}{r}\right]\right\}\right],
$$

taking into account the market clearing condition

$$
r \sum_{i=1}^{N}(1-\gamma)\left[\alpha_{i} R_{1}+\left(1-\alpha_{i}\right) p_{i} R_{2}\right]=\sum_{i=1}^{N} \gamma\left(1-\alpha_{i}\right)\left(1-p_{i}\right) R_{2}
$$

and incentive compatibility constraint for entrepreneurs $r \geq 1$.

Since all the banks are ex ante symmetric, bank $i$ 's problem in the market equilibrium is the same as the social planner's problem, the solution should be the same and constrained efficient. In addition, depositors' return $d_{0}$ doesn't depend on the bank's realized liquidity shock $p_{i}$, therefore, there is no bank run.

\section{References}

Allen, F., Carletti, E. and Gale, D. (2009), Interbank market liquidity and central bank intervention, Journal of Monetary Economics 56, 639-652.

Allen, F., Carletti, E. and Gale, D. (2014), Money, financial stability and efficiency, Journal of Economic Theory 149, 100-127.

Cao, J. and Illing, G. (2011), Endogenous exposure to systemic liquidity risk, International Journal of Central Banking 7, 173-216.

Diamond, D. and Rajan, R. (2001), Liquidity risk, liquidity creation and financial fragility: a theory of banking, Journal of Political Economy 109, 2431-2465.

Diamond, D. and Rajan, R. (2006), Money in a theory of banking, American Economic Review 96, 3053.

Diamond, D. W. and Rajan, R. G. (2012), Illiquid banks, financial stability, and interest rate policy, Journal of Political Economy 120, 552-591.

Freixas, X., Martin, A. and Skeie, D. (2011), Bank liquidity, interbank markets, and monetary policy, Review of Financial Studies 24, 2656-2692.

Hart, O. and Moore, J. (1994), A Theory of debt based on the inalienability of human capital, Quarterly Journal of Economics 109, 841-79.

Skeie, D. (2008), Banking with nominal deposits and inside money, Journal of Financial Intermediation 17, 562-584. 